\title{
Ionization energy and reduction potential in ferrocene derivatives. The effect of the exact exchange fraction in hybrid-DFT methods.
}

\author{
Mateja Toma ${ }^{1}$, Tea Kuvek ${ }^{1}$, and Valerije $\operatorname{Vrček}^{1}$ \\ ${ }^{1}$ University of Zagreb Faculty of Pharmacy and Biochemistry
}

June 22, 2020

\begin{abstract}
Hybrid density functionals have been regularly applied in state-of-the-art computational models for predicting reduction potentials. Benchmark calculations of the absolute reduction potential of ferricenium/ferrocene couple, the IUPAC-proposed reference in nonaqueous solution, include the B3LYP/6-31G(d)/LanL2TZf protocol. We used this procedure to calculate ionization energies and reduction potentials for a comprehensive set of ferrocene derivatives. The protocol works very well for a number of derivatives. However, a significant discrepancy $(>1 \mathrm{~V})$ between experimental and calculated data was detected for selected cases. Three variables were assessed to detect an origin of the observed failure: density functional, basis set, and solvation model. It comes out that the Hartree-Fock exchange fraction in hybrid-DFT methods is the main source of the error. The accidental errors were observed for other hybrid models like PBE0, BHandHLYP, and M06-2X. Therefore, hybrid DFT methods should be used with caution, or pure functionals (BLYP or M06L) may be used instead.
\end{abstract}

\section{Hosted file}

manuscript.docx available at https://authorea.com/users/334976/articles/461674-ionizationenergy-and-reduction-potential-in-ferrocene-derivatives-the-effect-of-the-exact-

exchange-fraction-in-hybrid-dft-methods 